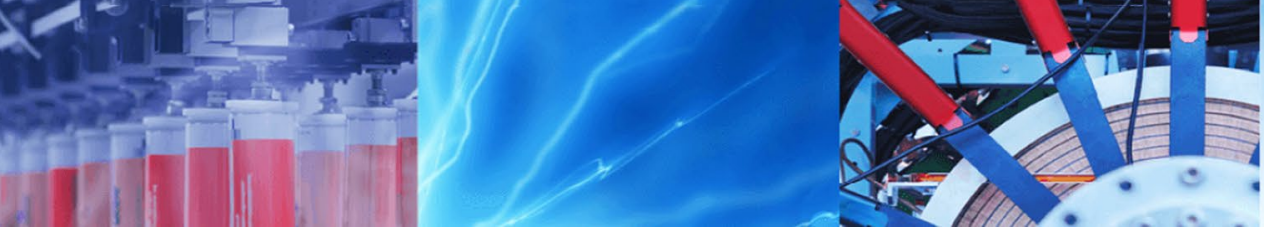

Research Article

\title{
Method of extraction and proteome profiling of mycobacteria using liquid chromatography-high resolution mass spectrometry
}

\author{
Amol Bajaj $^{1} \cdot$ Suraj Saraswat ${ }^{1,4} \cdot$ Joanna Freeke ${ }^{2,3} \cdot$ Adam Barker $^{1}$
}

Received: 6 June 2020 / Accepted: 13 October 2020 / Published online: 22 October 2020

(c) The Author(s) $2020 \quad$ OPEN

\begin{abstract}
Advances in massively parallel sequencing, of complete bacterial genomes, have led to many novel findings in the field of genomics. However, these data often lack correlation with expressed protein profiles. It has been demonstrated that even very closely related genomes, such as in mycobacteria, express drastically different phenotypes. These phenotypes often have major roles in pathogenicity. Therefore, it is just as important to have a method for examining the proteome of a bacterium as well as its genome. These studies are further complicated in mycobacteria due to the cell wall and mycolic acid. A comprehensive method for the identification and characterization of the whole mycobacterium protein profile is needed. In the present study, a simple, sensitive, and specific liquid chromatography tandem mass spectrometry method was developed for the extraction, purification and profiling the mycobacterial proteome in various species. During development, sonication and bead-beating cell lysis protocol was tested using 15\% Acetonitrile and $6 \mathrm{M}$ guanidine- $\mathrm{HCl}(\mathrm{GuHCl})$ as extraction solvent. Sonication lysis in $6 \mathrm{M} \mathrm{GuHCl}$ with glass beads was the preferred method for cell lysis. This method was developed using reverse phase liquid chromatography and a Q Exactive ${ }^{\mathrm{TM}}$ Plus Orbitrap ${ }^{\mathrm{TM}}$ mass spectrometer for peptide and protein identification. Bottom-up liquid chromatography-mass spectrometry LC-MS analysis resulted in identification of greater than 2500 proteins.
\end{abstract}

Keywords Mycobacterium · Sonication lysis · Extraction · Purification · Proteome · LC-MS

\section{Introduction}

Since the first structural studies of the Mycobacterium family, it has been recognized that the cell wall of it was vastly different from other bacteria. The presence of mycolic acid, long chain fatty acids and complex carbohydrates make the cell wall very difficult to break open and remove from other cellular debris [1-4]. Disruption of the cell membrane requires much harsher methods such as sonication, bead beating [5] and repeated French press runs. Typical extractions methods of protein and DNA require organic solvent extraction with the inclusion of phenol for complete phase separation. These studies are further complicated in mycobacteria due to the mycolic acid and extraction techniques needed to obtain a complete protein profile.

Over the last few years there have been many improvements in the performance of mass spectrometry (MS), making sure that any large-scale complex proteome

Amol Bajaj and Suraj Saraswat have contributed equally to this work.

Electronic supplementary material The online version of this article (https://doi.org/10.1007/s42452-020-03691-1) contains supplementary material, which is available to authorized users.

Amol Bajaj, amol.bajaj@aruplab.com; $\bowtie$ Adam Barker, adam.barker@aruplab.com | ${ }^{1}$ ARUP Institute for Clinical and Experimental Pathology, 500 Chipeta Way, Salt Lake City, UT 84108, USA. ${ }^{2}$ Centre for Infectious Diseases, Radboud UMC, Nijmegen, Netherlands. ${ }^{3}$ Thermo Fisher Scientific, Landsmeer, Netherlands. ${ }^{4}$ Present Address: Sotera Health, Salt Lake City, UT, USA. 
derived from cell or tissue lysates or from body fluids can be easily analyzed using MS based proteomic approach. [6-8].

Today, mass spectrometry is widely applied for identification, structural characterization [9], and absolute quantification [10] of proteins and their post-translational modifications. Protein MS analysis are typically conducted by electrospray ionization (ESI) and matrix-assisted laser desorption/ionization (MALDI) mass spectrometry [11, 12]. To analyze these complex proteomic samples, bottom-up and top-down MS techniques were developed as complimentary approaches to increase the information content of the experiment. In the top-down approach, a proteomic sample undergoes a separation step and individual intact proteins are investigated directly by tandem mass spectrometry (MS/MS). In the bottom-up approach, a protein mixture is subjected to enzymatic digestion, and high performance liquid chromatography-mass spectrometry (HPLC-MS) is then used for the separation of digested peptides and followed by identification of the individual peptides [13]. Reversed-phase HPLC (RP-HPLC) in combination with ESI-MS is most commonly used in such applications. The resolving power of the instrument is of utmost importance for high confidence identification and characterization of biological entities in peptide mapping experiments [6]. There have been a series of reports of several thousand-protein identifications obtained using the bottom-up approach [6-8]. However, there are no such reports available in public domain from mycobacterium species. Wang et. al. and He et. al. reported identification of only 901 and 390 proteins from the whole proteome and cell wall proteome, respectively, in $M$. smegmatis $[14,15]$. These studies were far from complete coverage of entire $M$. smegmatis proteome. Therefore, it would be indispensable to envision a protein profiling based LC-MS method to cover entire proteome for accurate identifications of clinically important species such as mycobacterium complexes.

Hence, we set out to develop a method for the extraction, purification, and profile the proteome in various mycobacterium species. The extraction solvents tested were $15 \% \mathrm{ACN}$ and $6 \mathrm{M} \mathrm{GuHCl} \mathrm{pH}$ 8.0. The lysis method tested was a bead-beating and sonication approach. The SPE purified proteins were then first separated using sodium dodecyl sulphate-polyacrylamide gel electrophoresis (SDS-PAGE) and peptides from in-gel digestion were then subjected to LC-MS/MS analysis. The method was developed using reverse phase liquid chromatography and a Q Exactive ${ }^{\mathrm{TM}}$ Plus Orbitrap ${ }^{\mathrm{TM}}$ mass spectrometer for peptide and protein identification.

\section{Materials and methods}

\subsection{Chemicals and reagents}

Guanidine Hydrochloride (GuHCl) (>99\% purity), sequence grade trypsin, iodoacetamide (IAM), and Dithiothreitol (DTT) (>95\% purity) were purchased from Sigma (St. Louis, MO) and dissolved in water for immediate use. Glass beads $(2.0 \mathrm{~mm}, 1.0 \mathrm{~mm}$, and $0.5 \mathrm{~mm})$ and high-purity (>95\%) formic acid were purchased from Sigma (St. Louis, MO). Optima LC-MS grade water and acetonitrile were purchased from Fisher Scientific (Fair Lawn, NJ). MOPS buffer, midi gels, loading dye, and benchmark protein ladder were purchased from Life Technologies (Grand Island, NY).

\section{Sample preparation}

\subsection{Preparation of whole cell extracts (WCE) for mycobacterium species}

To extract maximum amount of proteins, various extraction protocols were tested such as extraction with: different lysis methods (sonication without glass beads, sonication with glass beads of different sizes like $0.5 \mathrm{~mm}, 1.0 \mathrm{~mm}$, and $2.0 \mathrm{~mm}$, and bead beating with glass beads of size $0.5 \mathrm{~mm}$ ) and different extraction solvents $(6 \mathrm{M} \mathrm{GuHCl}, \mathrm{pH}$ 8 and $15 \%$ acetonitrile (ACN)).

\subsubsection{WCE preparation using bead-beating lysis method}

Mycobacteria were cultured on $7 \mathrm{H} 11$ agar plates (Hardy Diagnostics) for 3-4 days and approximately 5-6 mg of microbes were placed into a low protein binding (LBE) Eppendorf tube. Microbes were then washed with $1 \mathrm{~mL}$ of PBS to remove exogenous proteins. Next, the LBE tube was centrifuged for $2 \mathrm{~min}$ at $10 \mathrm{Kg}(10,000 \mathrm{rcf}$ speed) and the PBS buffer was removed. The pellet $(5 \mathrm{mg})$ was suspended in $200 \mu \mathrm{L}$ of lysis buffer ( $6 \mathrm{M} \mathrm{GuHCl} \mathrm{pH} 8.0$ or $15 \% \mathrm{ACN}$ ) in a $200 \mu \mathrm{L} / 5 \mathrm{mg}$ (instead of this defining as concentration it is just re-stating that $5 \mathrm{mg}$ of microbe was resuspended in $200 \mu \mathrm{L}$ of lysis buffer, this representation can be removed if it is confusing for the readers) microbe solution. Next, $100 \mu \mathrm{L}$ of $0.5 \mathrm{~mm}$ glass beads were added to the beadbeating vials and the resulting $200 \mu \mathrm{L}$ microbe suspension was transferred to lysis vials. The microbes were lysed 5 times with one-minute cycles of Fast Prep bead beater at a speed of $6.0 \mathrm{~m} / \mathrm{s}$ with no rest between each cycle. Cell lysate was incubated for $10 \mathrm{~min}$ after bead-beating at room temperature. Cell lysate was centrifuged for $5 \mathrm{~min}$ at $10 \mathrm{~K} \mathrm{~g}$ and the supernatant was transferred to new 
LBE vial. The amount of proteins extracted was measured using Bradford assay (Quick Start ${ }^{\mathrm{TM}}$ Bradford Protein Assay, Bio-Rad) for $6 \mathrm{M} \mathrm{GuHCl}$ extraction solvent or Qubit assay (Qubit ${ }^{\text {TM }}$ Protein Assay Kit, Thermo Fisher Scientific) for 15\% ACN extraction solvent. The extract was stored $-80^{\circ} \mathrm{C}$ until further use.

\subsubsection{WCE preparation using sonication lysis method}

Mycobacteria were cultured, washed and microbes solution was prepared as 2.2.1.1. A $100 \mathrm{uL}$ portion of $0.5 \mathrm{~mm}$ glass bead was added to the sonication vials and the $200 \mathrm{uL}$ microbes suspension was transferred to the lysis vials. The microbes were lysed using sonication for $2.5 \mathrm{~min}$ at $50 \%$ amplitude at a force of $200 \mathrm{gm}$ from top. The cell lysate was then transferred to new LBE vial and centrifuged for $5 \mathrm{~min}$ at $10 \mathrm{Kg}$. The supernatant was collected in new LBE vial. The amount of proteins extracted was measured using Bradford assay for $6 \mathrm{M} \mathrm{GuHCl}$ extraction solvent or Qubit assay for $15 \%$ ACN extraction solvent. The extract was stored $-80^{\circ} \mathrm{C}$ until further use.

\subsection{Purification of WCE}

A number of cleanup methods (these are the products/ kits available from specific vendors and I have described all the methods below using them for those products. Also, other purification methods are general filtration/precipitation/liquid-liquid separation) were tested for purification of WCE such as Cleanascite treatment, DNase Treatment, Liquid-liquid extraction, Lipid extraction, Protein precipitation, $0.45 \mu \mathrm{m}$ filtration, size-exclusion columns, C18 SPE columns, C4 SPE columns, POROS RP SPE columns considering phenotypic properties of mycobacteria.

\subsubsection{Cleanascite treatment (biotech support group) protocol}

Cleanascite reagent was added to WCE in following stoichiometry (Cleanascite:WCE::1:5). The reaction mixture was then incubated for $15 \mathrm{~min}$ at room temperature. After incubation, the mixture was centrifuged at $10 \mathrm{Kg}$ for $5 \mathrm{~min}$. The supernatant containing proteins was carefully collected in a new LBE vial. The Bradford assay was performed on supernatant for protein concentration measurement. A $25 \mu \mathrm{g}$ portion of the WCE preparation was used to run the SDS-PAGE gel.

\subsubsection{DNase I treatment (thermo fisher scientific) protocol}

A $25 \mu \mathrm{L}$ volume of DNase I (1 unit/ $\mu \mathrm{L}$ ) was added to the tube containing WCE pellet. This reaction mixture was incubated at $37^{\circ} \mathrm{C}$ for approximately an hour. After incubation, the mixture was centrifuged at $10 \mathrm{~K} \mathrm{~g}$ for $5 \mathrm{~min}$. The supernatant containing the protein extract was carefully collected in a new LBE vial. A Bradford assay was performed on supernatant for protein concentration measurement. A $25 \mu \mathrm{g}$ portion of the cleaned WCE extract was then loaded and run on a SDS-PAGE gel.

\subsubsection{Liquid-liquid extraction protocol}

A $300 \mu \mathrm{L}$ volume of chloroform was added to the tube containing and equal volume of WCE extract. After a 1 min vortex step, the 2 layers were allowed to separate for $5 \mathrm{~min}$. The bottom organic layer was carefully removed and discarded. Another $300 \mu \mathrm{L}$ of chloroform was added to the remaining (top) aqueous layer containing the proteins of interest, followed by a 1 min vortexing step. The bottom organic layer was again carefully removed and discarded. The aqueous phase was dried for $15 \mathrm{~min}$ to evaporate any remaining chloroform and was used for further experiments. The Bradford assay was performed for protein concentration measurement. A $25 \mu \mathrm{g}$ of cleaned WCE was used to run SDS-PAGE gel.

\subsubsection{Lipid extraction treatment (cell biolabs Inc.) protocol}

$500 \mu \mathrm{L}$ of Lipid Extraction Reagent A from a lipid extraction kit (Cell BioLabs Inc.) was added to the tube containing $100 \mu \mathrm{L}$ of the WCE extract and was vortexed for $10 \mathrm{~min}$. A $250 \mu \mathrm{L}$ volume of Lipid Extraction Reagent $B$ from the kit was added to the tube and vortexed for $5 \mathrm{~min}$. An additional $250 \mu \mathrm{L}$ volume of Lipid Extraction Reagent $B$ from the kit was added to the tube and vortexed for an additional $5 \mathrm{~min}$. Next, a $500 \mu \mathrm{L}$ volume of Lipid Extraction Reagent $C$ from kit was added to the tube and was vortexed for an additional $5 \mathrm{~min}$. The final mixture was then centrifuged at $1 \mathrm{Kg}$ for $5 \mathrm{~min}$. The top organic layer containing lipids was carefully removed and discarded. A $530 \mu \mathrm{L}$ volume of Lipid Extraction Reagent $B$ from the kit was added to the remaining (bottom) aqueous layer and was vortexed for $5 \mathrm{~min}$. The tube was centrifuged at $1 \mathrm{~K} \mathrm{~g}$ for $5 \mathrm{~min}$. The top organic layer containing lipids was carefully removed and discarded. A $420 \mu \mathrm{L}$ volume of Lipid Extraction Reagent B from the kit was added to the remaining (bottom) aqueous layer and was vortexed for $5 \mathrm{~min}$. The tube was centrifuged at $1 \mathrm{~K} \mathrm{~g}$ for $5 \mathrm{~min}$. The top organic layer containing lipids was carefully removed and discarded. The remaining (bottom) aqueous layer was then used for further experiments. The Bradford assay was performed for protein concentration measurement. A $25 \mu \mathrm{g}$ of cleaned WCE was used to run SDS-PAGE gel. 


\subsubsection{Protein precipitation (acetone precipitation) protocol}

Ice-cold acetone was added at a ratio of 2:1 to the WCE extract. The sample and reagents were kept in ice-water bath all the times during the procedure. The reaction mixture was then incubated at $-20^{\circ} \mathrm{C}$ overnight. The following day, the tube was centrifuged for $5 \mathrm{~min}, 10 \mathrm{Kg}$ at $4^{\circ} \mathrm{C}$. The resulting pellet was then washed twice with $500 \mu \mathrm{L}$ ice-cold $100 \%$ acetone and once with $80 \%$ acetone. The tube was centrifuged for $5 \mathrm{~min}, 10 \mathrm{Kg}$ at $4^{\circ} \mathrm{C}$ and air dried The pellet was suspended in water for further experiments. The Bradford assay was then performed for protein concentration measurement. A $25 \mu \mathrm{g}$ of cleaned WCE was used to run SDS-PAGE gel.

\subsubsection{Filtration $(0.45 \mu \mathrm{m})$ protocol}

The WCE extract was diluted six times to bring the $\mathrm{GuHCl}$ concentration down to $1 \mathrm{M}$ and was used with no dilution in the $15 \%$ ACN extraction solvent. The diluted WCE extract was then passed through a $0.45 \mu \mathrm{m}$ filter. The filtrate was collected and used for further experiments. The Bradford assay was then performed for protein concentration measurement. A $25 \mu \mathrm{g}$ of cleaned WCE was used to run SDS-PAGE gel.

\subsubsection{PD MiniTrap Sephadex G-25 (GE Healthcare) desalting protocol}

The whole cell extract (WCE) was then diluted with sodium phosphate so that the total volume of WCE and buffer added equals $1 \mathrm{~mL}$. A PD MiniTrap Sephadex G-25 Desalting column was shaken to resuspend the medium and allowed the medium to settle down. The top and bottom caps were removed and allowed the column storage solution to flow out. The column was equilibrated with $8 \mathrm{~mL}$ ammonium bicarbonate $(50 \mathrm{mM})$. The diluted extract was loaded into the column so that the extract covered the packed bed completely. Next, elution was performed with $500 \mu \mathrm{L}$ ammonium bicarbonate $(50 \mathrm{mM})$ solution. The Bradford assay was then performed on eluent for protein concentration measurement. A $25 \mu \mathrm{g}$ of cleaned WCE was used to run SDS-PAGE gel.

\subsubsection{C4 SPE (perkin elmer) protocol}

The whole cell extract (WCE) was diluted with $0.1 \%$ FA in water 1:6. C4 cartridge was conditioned with $3 \mathrm{~mL}$ of $0.1 \%$ FA in ACN and equilibrated the cartridge with $3 \mathrm{~mL} 0.1 \% \mathrm{FA}$ in water. A $3 \mathrm{~mL}$ volume of diluted WCE was loaded into the cartridge. The cartridge was washed with $3 \mathrm{~mL} 0.1 \%$ FA in $4 \%$ $A C N$ and the entire wash solution was pushed out of the cartridge by using a syringe. A $300 \mu \mathrm{L}$ elution solvent $0.1 \%$ FA in $60 \% \mathrm{ACN}$ was allowed to enter into the cartridge. At this time, the flow was stopped and incubated for approx. $5 \mathrm{~min}$. The elution solvent was then pushed out of the cartridge by using the syringe and collected into new LBE. The eluent was speed-vac dried and suspended in water for further experiments. Bradford assay was performed on eluent for protein concentration measurement. A $25 \mu \mathrm{g}$ of cleaned WCE was used to run SDS-PAGE gel.

\subsubsection{POROS RP2 SPE (glygen corporation) protocol}

The POROS RP 2 stage-tip was conditioned with $100 \mu \mathrm{L}$ $0.1 \% \mathrm{FA}$ in ACN. The stage-tip was equilibrated with $100 \mu \mathrm{L}$ $0.1 \%$ FA in water and repeated 2 times. A $50 \mu \mathrm{g}$ portion of WCE was then loaded into the stage-tip. The stage-tip was washed with $100 \mu \mathrm{L} 0.1 \% \mathrm{FA}$ in $4 \% \mathrm{ACN}$ and repeated 2 times. Proteins bound to the matrix were eluted with $100 \mu \mathrm{L}$ $0.1 \% \mathrm{FA}$ in $60 \% \mathrm{ACN}$ and repeated 2 times. The eluent was speed-vac dried and suspended in water for further experiments. The Bradford assay was performed on eluent for protein concentration measurement. A $25 \mu \mathrm{g}$ of cleaned WCE was used to run SDS-PAGE gel. Before loading the extract on the gel, the sample was subjected to reduction and alkylation using DTT and IAM, respectively, as described by Villen et. al.[16]. Briefly, $500 \mathrm{mM}$ DTT was added to approximately $200 \mu \mathrm{g}$ of extract such that the final DTT concentration was $5 \mathrm{mM}$ in the reaction mixture. The mixture was then incubated at $56^{\circ} \mathrm{C}$ for $30 \mathrm{~min}$. After the reaction mixture cooled to room temperature, $700 \mathrm{mM}$ IAM was added to a final concentration of $14 \mathrm{mM} \mathrm{IAM}$ and was allowed to react for $30 \mathrm{~min}$ in dark. DTT was added again with $5 \mathrm{mM}$ final concentration and kept in dark at room temperature for $15 \mathrm{~min}$. A $25 \mu \mathrm{g}$ portion of cleaned, reduced, and alkylated WCE was then separated on a SDS-PAGE gel.

\section{Protein separation by SDS-PAGE and in-gel digestion of proteins}

A $25 \mu \mathrm{g}$ WCE aliquots were separated by SDS-PAGE (4-12\% midi gel) and stained with Coomassie Blue dye (Bio-Rad) according to the manufacturer's instructions. Twelve bands were excised equally over the length of molecular weight ladder from 220 to $10 \mathrm{~K} \mathrm{Da}$ and the gel pieces were placed in separate tube for in-gel digestion. After in-gel digestion, two bands were combined to prepare six peptide samples for LC-MS analysis.

\section{Instrumentation and data acquisition}

All experiments were performed by Easy nano-LC-ESI-MS. The Easy-nLC system used was $\mathrm{nLC} 1000$ (Thermo Fisher, San Jose, California). The $\mathrm{nLC}$ was connected to a hybrid 
quadrupole-Orbitrap mass spectrometer ( $Q$ Exactive Plus, Thermo Fisher, San Jose, CA, USA). The $\mathrm{nLC}$ and mass spectrometer were controlled by Xcalibur software version 3.0 from Thermo Fisher Scientific. The mass spectrometer was operated in positive ESI mode.

\section{LC-MS analysis of peptides and data analysis}

Chromatographic separation of peptides was done on a Thermo easy spray $3 \mu \mathrm{m}, 15 \times 75 \mu \mathrm{m}$ C18 column. The column was maintained at a temperature of $45^{\circ} \mathrm{C}$. Elution was done according to the following method: At 0 min $5 \%$ of B, $54 \mathrm{~min} 28 \%$ of B, 1 min $90 \%$ of B, 5 min $90 \%$ of B, for a total elution time of $60 \mathrm{~min}$. Mobile phase $A$ was $0.1 \%$ FA in water and mobile phase B was $0.1 \%$ FA in ACN. The flow rate was $300 \mathrm{~nL} / \mathrm{min}$ and $3 \mu \mathrm{L}(\sim 400 \mathrm{ng})$ of each sample was injected onto the column.

Mass analysis of peptides was performed in the $\mathrm{m} / \mathrm{z}$ range from 400 to 1600 . The general mass spectrometric conditions were: spray voltage $2.0 \mathrm{kV}$, capillary temperature $325^{\circ} \mathrm{C}$, and collision energy $27.0 \mathrm{~V}$ normalized collision energy (NCE). The MS scan time was $1.0 \mathrm{~s}$ with 1 microscan (used for both MS and MS/MS modes of operation). The AGC target was $1 \mathrm{e}^{6}$ and $5 \mathrm{e}^{4}$ for MS and MS/MS, respectively. Resolution was set to 70,000 and 17,500 for MS and MS/MS, respectively.

LC-MS/MS data was processed using Proteome Discov$\operatorname{erer}^{\mathrm{TM}}$ (PD) Software (version 1.4.0.288, Thermo Fisher Scientific).The MS/MS spectra were searched using SEQUEST search engine against mycobacterium database downloaded from Uniprot. The precursor mass tolerance was confined within $20 \mathrm{ppm}$ with fragment mass tolerance of $0.02 \mathrm{Da}$. Oxidation of methionine (15.995 Da) and N-terminus Acetylation (42.011 Da) were chosen as dynamic modifications. The carbamidomethylation of cysteine $(57.021 \mathrm{Da})$ was chosen as a static modification. The enzyme specificity was set to trypsin with a maximum of three modifications per peptide and 2 miss cleavage were allowed. Assigned peptides were filtered with $1 \%$ false discovery rate (FDR) and 2 peptide per protein is used to confirm a true protein identification.

\section{Results and discussion}

To understand the correlation between genotype, phenotypes, and pathogenicity, we studied the proteome of different mycobacterial species from their WCE. The whole proteome from mycobacterial species is less acknowledged in clinical world among closely related pathogens even after the fact that it can provide most valuable information about pathogenicity. The proteome analysis is complicated in mycobacteria due to the mycolic acid and extraction techniques needed to obtain a complete protein profile. This study involved development and optimization of protein extraction and purification protocols, with a thorough identification of the mycobacterial proteome.

WCE were prepared by lysing microbes using 2 lysis methods: sonication and bead beating (BB). The $6 \mathrm{M}$ $\mathrm{GuHCl}, \mathrm{pH} 8$ and $15 \% \mathrm{ACN}$ solutions were used as extraction solvents. The amount of protein $(\mu \mathrm{g})$ extracted per $\mathrm{mg}$ of wet weight of cells from the methods described herein were calculated from Bradford assay. The effect of the amount of wet weight of cells on extracted amount of proteins were measured (Fig. 1) for both sonication and BB lysis methods with similar amount of protein $(\mu \mathrm{g} / \mathrm{mg})$ extracted independent of the wet weight.

Average amount of proteins extracted for $\sim 5 \mathrm{mg}$ of wet weight of cells for $\mathrm{GuHCl}$ as extraction solvent with sonication lysis methods is approximatel $30 \mu \mathrm{g}, 33 \mu \mathrm{g}$, and $30 \mu \mathrm{g}$ for M. fortuitum, M. abscessus, and M. chelonae, respectively and with BB lysis method is $15 \mu \mathrm{g}, 16 \mu \mathrm{g}$, and $19 \mu \mathrm{g}$ for $M$. fortuitum, M. abscessus, and $M$. chelonae, respectively (Table 1 and 2). Similarly, average amount of proteins extracted from $\sim 5 \mathrm{mg}$ of wet weight of cells for $15 \%$ ACN as extraction solvent with sonication lysis methods is approximately $6 \mu \mathrm{g}, 11 \mu \mathrm{g}$, and $18 \mu \mathrm{g}$ for $M$. fortuitum, $M$. abscessus, and $M$. chelonae, respectively and with $\mathrm{BB}$ lysis method is $16 \mu \mathrm{g}, 14 \mu \mathrm{g}$, and $16 \mu \mathrm{g}$ for $M$. fortuitum, $M$. abscessus, and $M$. chelonae, respectively (Table 1 and 2). It was observed that protein extraction efficiency decreased with increased wet weight of cells for the $15 \%$ ACN buffer with sonication lysis method. However, no such trend was detected for the 15\% ACN buffer with BB lysis method. On the other hand, upward trend was observed for protein extraction efficiency for the $\mathrm{GuHCl}$ extraction solvent with both sonication and BB lysis methods. This trend was more apparent with sonication lysis method. Therefore, it is clear that sonication lysing method with $6 \mathrm{M} \mathrm{GuHCl}, \mathrm{pH}$ 8 as extraction solvent is extracting more protein amount than any other combination of lysis method and extraction solvent. This could be due to strong denaturation property of $\mathrm{GuHCl}$, which may helping cells to solubilize, lyse, and denature proteins.

Sonication was the preferred lysing method when $6 \mathrm{M} \mathrm{GuHCl}$ was used as extraction solvent while there was no preferred choice for lysis method with $15 \%$ ACN as extraction solvent. The preferred method of protein extraction is sonication in $6 \mathrm{M} \mathrm{GuHCl}$ utilizing glass beads. This method consistently extracted more proteins than the other solvents and bead beating methods. It was found that the size of the bead and the number of beads had no significant effect on protein concentration 

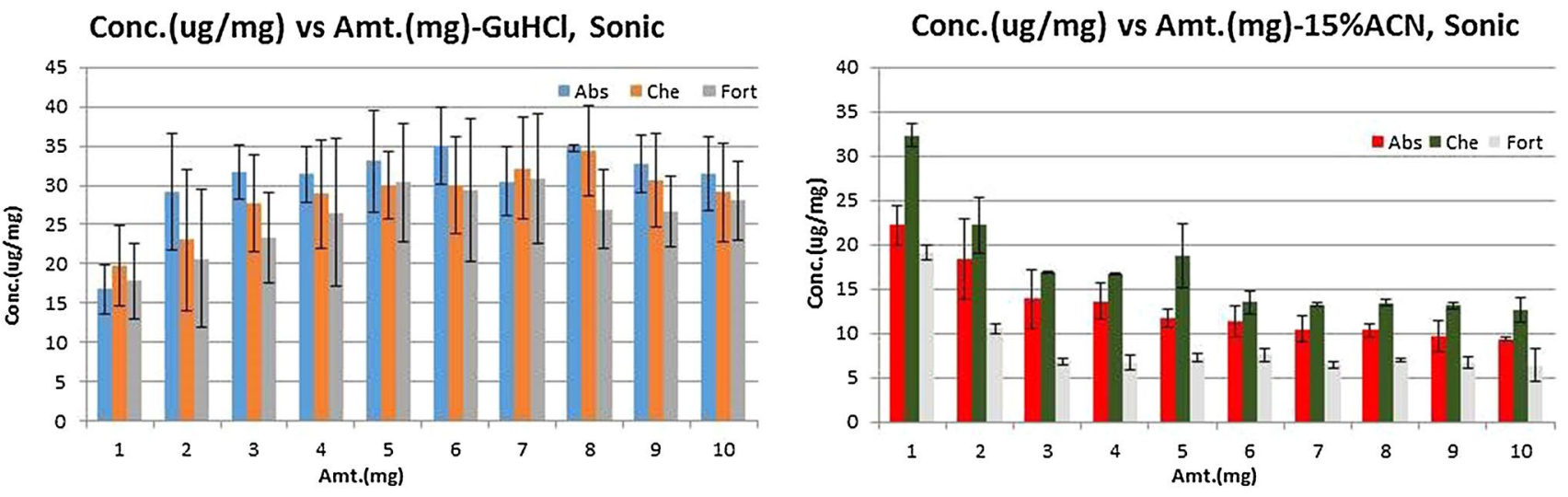

Conc.(ug/mg) vs Amt.(mg)-GuHCl, BB

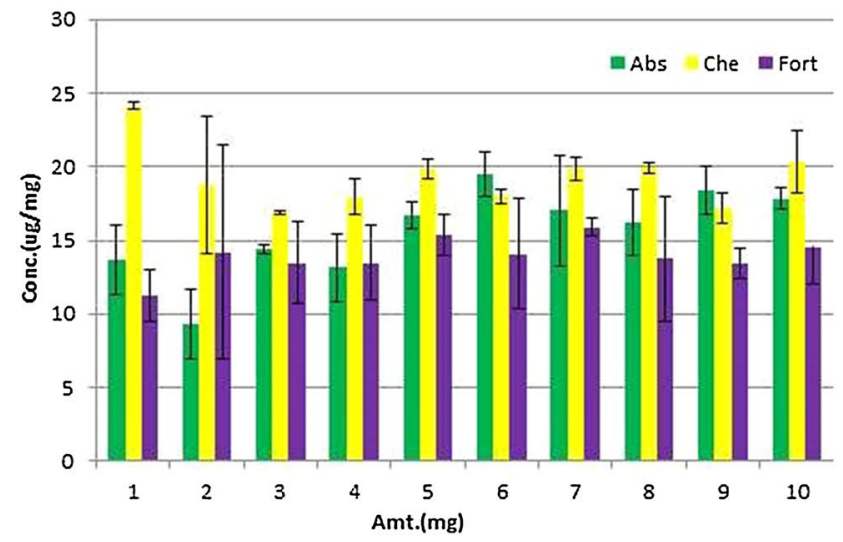

Conc. (ug/mg) vs Amt.(mg)-15\%ACN, BB

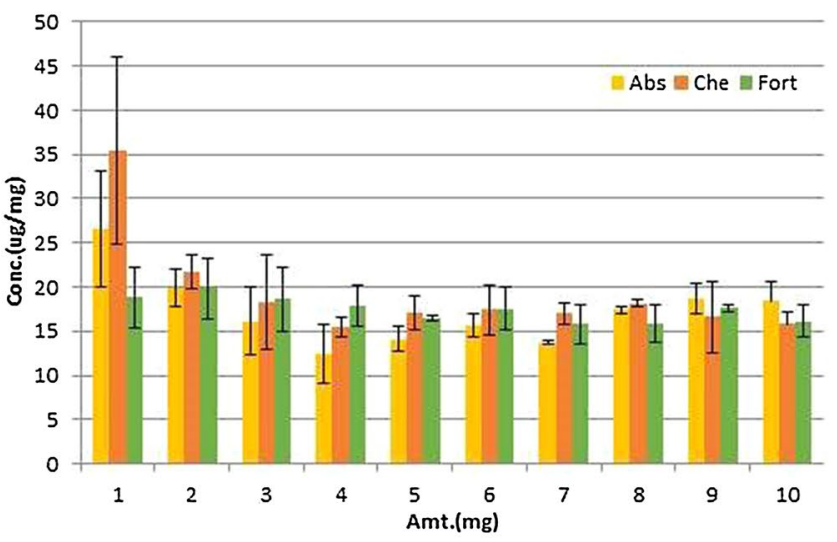

Fig. 1 (Color). Plot of amount of proteins extract $(\mu \mathrm{g} / \mathrm{mg})$ vs amount (wet weight, $\mathrm{mg}$ ) of cell used for lysis for sonication and bead beating (BB) lysis method with two extraction solvents. $\mathrm{Abs}=M$. abscessus, $\mathrm{Che}=M$. chelonae, $\mathrm{Fort}=M$. fortuitum

Table 1 Bradford Assay results of proteins extracted with $6 \mathrm{M} \mathrm{GuHCl}$ as extraction solvent using Sonication and Bead Beating as lysis method for $\sim 5 \mathrm{mg}$ wet weight

Approx. Conc. $(\mu \mathrm{g} / \quad$ Lysis Condition

$\mathrm{mg})$

Sonication

M. fortuitum (6841) 30

M. abscessus $(19,977)$

M. chelonae $(35,751)$

Bead-Beating

M. fortuitum (6841) 15

M. abscessus $(19,977)$

M. chelonae $(35,751)$

$50 \%$ Amplitude, 2.5 min,with $100 \mathrm{uL} 0.5 \mathrm{~mm}$ glass beads, $200 \mathrm{gm}$ weights

$50 \%$ Amplitude, $2.5 \mathrm{~min}$,with $100 \mathrm{uL} 0.5 \mathrm{~mm}$ glass beads, $200 \mathrm{gm}$ weights

$50 \%$ Amplitude, 2.5 min,with $100 \mathrm{uL} 0.5 \mathrm{~mm}$ glass beads, 200 gm weights

5 min bead-beating with $100 \mathrm{uL} 0.5 \mathrm{~mm}$ glass beads

$5 \mathrm{~min}$ bead-beating with $100 \mathrm{uL} 0.5 \mathrm{~mm}$ glass beads

5 min bead-beating with $100 \mathrm{uL} 0.5 \mathrm{~mm}$ glass beads when $0.5 \mathrm{~mm}, 1.0 \mathrm{~mm}$, and $2.0 \mathrm{~mm}$ glass beads were tested (Fig. 2). However, presence of beads were shown to be necessary for lysing cells during sonication as a small amount of proteins extracted when no bead was present during lysis.

It was also found that number of beads make no significant difference in extracted protein amount since similar amounts were extracted with 1 bead, 3 beads, and 15 beads of $2 \mathrm{~mm}$ size (Fig. 3).

Gels loaded with 15\%ACN WCE show no streaking and smearing for any of the tested mycobacterium species as shown in Fig. 4. However, a great extent of streaking and smearing was observed when WCE prepared in Gu$\mathrm{HCl}$ was loaded on gel as shown in supplementary Fig. 1 
Table 2 Qubit Assay results of Proteins extracted with $15 \%$ ACN as extraction solvent using sonication and bead beating as lysis method for $\sim 5 \mathrm{mg}$ wet weight

\begin{tabular}{ll}
\hline Approx. & Lysis Condition \\
Conc. $(\mu \mathrm{g} /$ & \\
$\mathrm{mg})$
\end{tabular}

Sonication

M. fortuitum (6841) 6

M. abscessus $(19,977) 11$

M. chelonae $(35,751) \quad 18$

Bead Beating

M. fortuitum (6841) 16

M. abscessus $(19,977) \quad 14$

M. chelonae $(35,751) \quad 16$

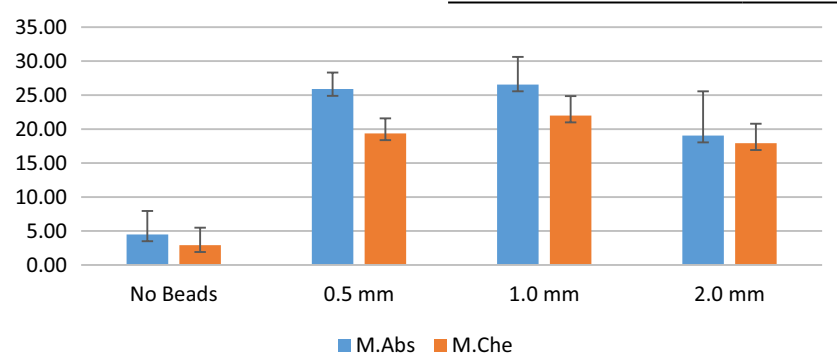

Fig. 2 Plot of amount of proteins extract $(\mu \mathrm{g} / \mathrm{mg}$ ) vs glass bead size used for sonication lysis method with $\mathrm{GuHCl}$ as extraction solvents. Abs $=M$. abscessus, Che $=M$. chelonae

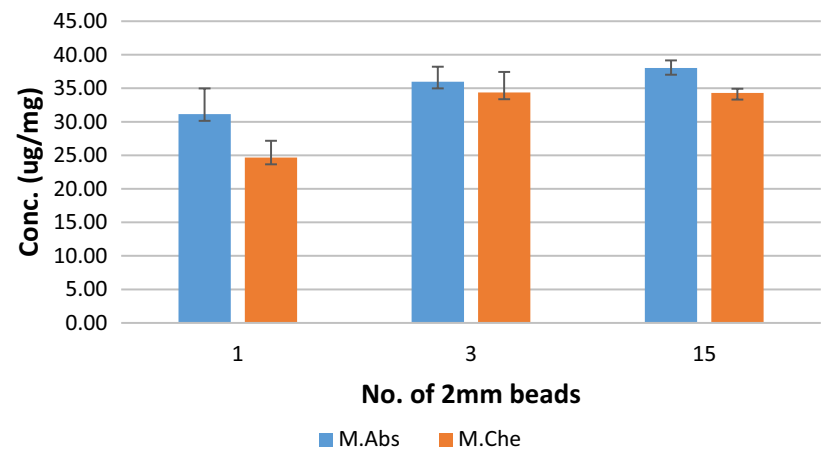

Fig. 3 Plot of amount of proteins extract $(\mu \mathrm{g} / \mathrm{mg})$ vs number of $2 \mathrm{~mm}$ glass bead used for sonication lysis method with $\mathrm{GuHCl}$ as extraction solvents. Abs $=M$. abscessus, $\mathrm{Che}=M$. chelonae

(lane 1 and 2). This could be due to complexity of mycobacterium cell wall $[17,18]$. It is very important to obtain nice and clear gel bands because they can be expected to distinguish different mycobacterial species by visual inspection [19] or more specifically with densitometric analysis [20] in addition to molecular [21] and MALDI [22] techniques.

Different strategies (liquid-liquid extraction, cleanascite lipid removal reagents, lipid extraction treatment,
$50 \%$ Amplitude, 2.5 min,with $100 \mathrm{uL} 0.5 \mathrm{~mm}$ glass beads, $200 \mathrm{gm}$ weights

$50 \%$ Amplitude, 2.5 min,with $100 \mathrm{uL} 0.5 \mathrm{~mm}$ glass beads, $200 \mathrm{gm}$ weights

$50 \%$ Amplitude, $2.5 \mathrm{~min}$, with $100 \mathrm{~L} 0.5 \mathrm{~mm}$ glass beads, $200 \mathrm{gm}$ weights

$5 \mathrm{~min}$ bead-beating with $100 \mathrm{uL} 0.5 \mathrm{~mm}$ glass beads

$5 \mathrm{~min}$ bead-beating with $100 \mathrm{uL} 0.5 \mathrm{~mm}$ glass beads

$5 \mathrm{~min}$ bead-beating with $100 \mathrm{uL} 0.5 \mathrm{~mm}$ glass beads

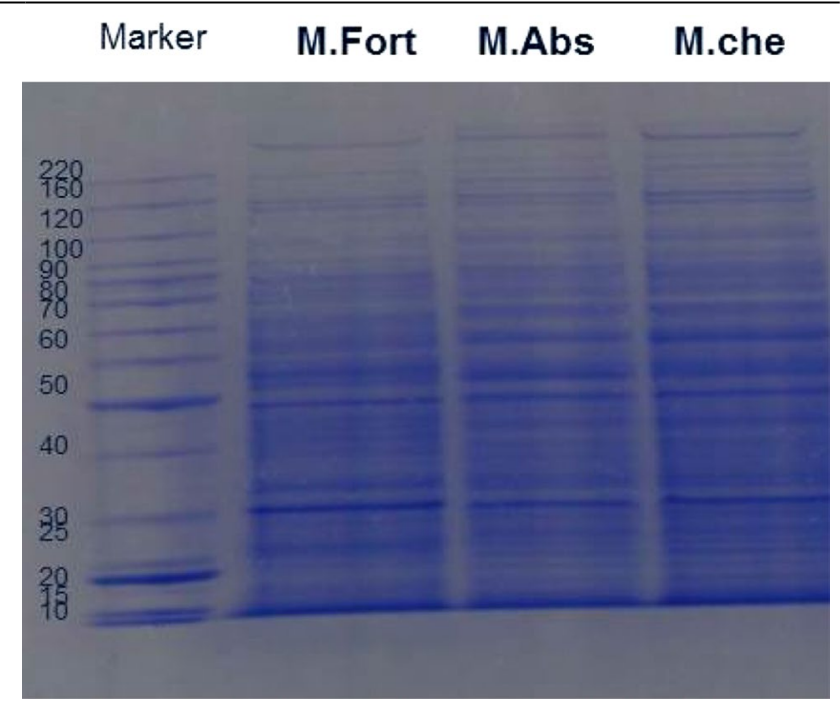

Fig. 4 (Color). Gel image of WCE of M. fortuitum, M. abscessus, and M. chelonae prepared using bead-beat lysis method with $15 \%$ ACN as extraction solvent. $25 \mu \mathrm{g}$ proteins were loaded on $4-12 \%$ gel

protein precipitation, DNase I treatment, 0.45 um filtration) were tested to clean-up WCE, minimize complexity, and to increase recovery of total protein. WCE prepared were treated with one or combination of these clean-up methods and, after treatment, loaded on gel to see effect of clean-up method on composition of extract. Most of the clean-up methods were not successful in cleaning WCE and, therefore, there was no improvement in gel pattern before and after treatment.

Liquid-liquid extraction clean-up method could not clean WCE composition, as streaking and smearing were still present as can be seen in supplementary Fig. 1 (lane 3 and 4). On the other hand, in lipid extraction clean-up method, proteins could not be recovered after treatment and no protein bands were detected on gel after clean up as shown in supplementary Fig. 1 (lanes 5-8). Similarly, proteins could not be recovered from WCE using 
other clean-up methods such as DNase I treatment, Cleanascite treatment, C4 SPE.

Proteins could also not be purified using protein precipitation sample clean-up. Whole cell extract (WCE) could not be passed through $0.2 \mu \mathrm{m}$ filter but managed to get through $0.45 \mu \mathrm{m}$ filters. Passing through $0.45 \mu \mathrm{m}$ filter was able to clean WCE to some extent but recovery of protein was so less that it was not feasible to use filtration as cleanup method.

The aforementioned strategies were less effective than cleaning the cell lysate with PD10 size-exclusion columns (Sephadex G-25, GE Healthcare). PD10 size-exclusion columns clean-up method were able to recover proteins as well as significantly removed streaking and smearing from SDS-PAGE gels. Use of ammonium bicarbonate buffer during elution from these columns was limiting step for future LC-MS experiments. Therefore, desalted WCE was further treated with DNase I and subjected to C4 SPE. Subsequent treatment of desalted WCE with DNase I did not result in loss of protein bands from gel. On the other hand, C4 SPE of desalted WCE resulted in loss of protein bands from gel which indicates that C4 SPE is still not a good option for mycobacterium protein purification. Nevertheless, this shows that desalting clean-up method can be used for purification of WCE. However, there was still need for another more feasible method for WCE clean up due to concern associated with use of desalting column and required buffers.

Therefore, different routinely used SPE cartridges such as C4, Biotage SPE cartridge were tested for clean up. Yet, recoveries of intact proteins from $\mathrm{C} 4$ and Biotage SPE were less than expected due to complexity of mycobacterium cell wall. On the other hand, the use of TopTip POROS RP2 (10-200 $\mu \mathrm{L}$, Glygen Corporation) SPE tips significantly increased protein recovery. POROS RP2 top-tip stage tip was able to clean-up sample as shown in Fig. 5 for all 3 tested species. Consequently, POROS RP2 top-tip stage tip cleaned WCE was used for bottom-up protein identification and characterization applications.

Bottom-up analysis of POROS RP2 SPE cleaned WCE was performed on C18 PepSwift Easy-nLC 1000-Q Exactive ${ }^{\mathrm{TM}}$ Plus mass spectrometer. Proteins were identified using SEQUEST searches in the Proteome Discoverer ${ }^{\mathrm{TM}}$ (PD) Software (version 1.4, Thermo Scientific). Proteome Discoverer analysis identified greater than 2500 proteins, including all of the ribosomal proteins, cytoplasmic, intracellular and membrane proteins from tested species (details of proteins identified from $M$. fortuitum and $M$. abscessus is mentioned in the supplemental data). All the experiments were performed in duplicates to achieve more coverage of mycobacterial species proteome. These mycobacterium species have $\sim 5000$ predicted coding sequences (CDS) [23] and consider the fact that not all of genes codes

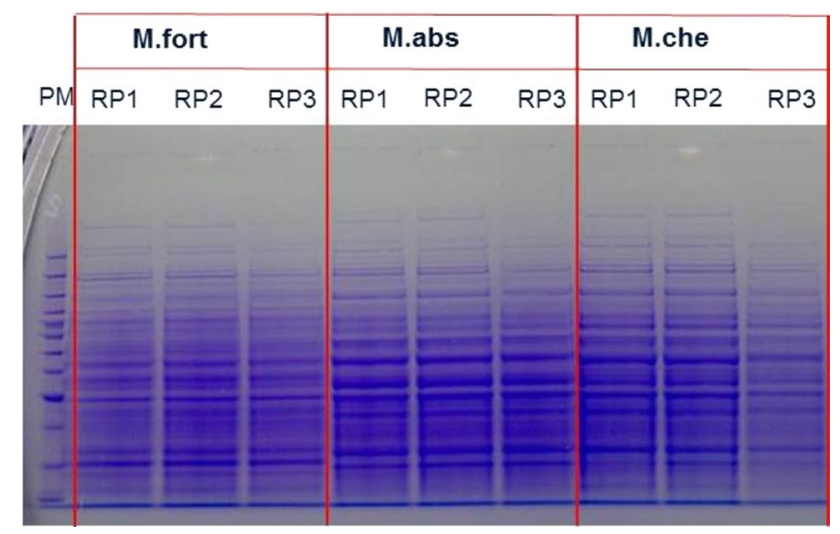

Fig. 5 Gel image of POROS RP2 SPE cleaned WCE of $M$. fortuitum, $M$. abscessus, and $M$. chelonae prepared using sonication lysis method with $\mathrm{Gu}-\mathrm{HCl}$ as extraction solvent. 25 ug proteins were loaded on $4-12 \%$ gel

for protein, in this study, we were able to identify most of the expressed protein. Comparison of protein profile for sonication and bead-beating lysis methods with $\mathrm{Gu}$ $\mathrm{HCl}$ extraction solvents is shown in Fig. 6 for M. Abs and $M$. Fort. It was observed that bead-beating lysis method yields increased number of proteins. So bead-beating can be used as preferred lysis method for mycobacteriums but there is still few hundred proteins which are specific with sonication lysis so a combination of both methods can be used for increased identification (Fig. 6).

\section{Conclusion}

The 2 lysis methods were utilized for WCE preparation using 2 extraction buffers and number of different cleanup methods tested for WCE treatment from various mycobacterium species. The sonication lysis method was preferred choice for microbe's lysis with $6 \mathrm{M} \mathrm{GuHCl}, \mathrm{pH} 8$ as extraction solvent; however, either lysis method can be used for cell lysis with extraction solvent of choice. Most of the tested clean-up methods were not effective in purifying proteins. Desalting and POROS RP2 SPE methods were practical in purifying proteins to great extent. POROS RP2 SPE clean-up method was chosen as method of choice due to ease in handling and further scope for automation. Developed methodologies for whole cell extraction (WCE) extraction and lysate clean up lead to identification of more than 2500 proteins in bottom-up LC-MS/MS approach from mycobacterium species. Comprehensive investigation of protein profile and identification of unique proteins from these mycobacteriums will provide us more insight into pathogenicity related to these microbes. 

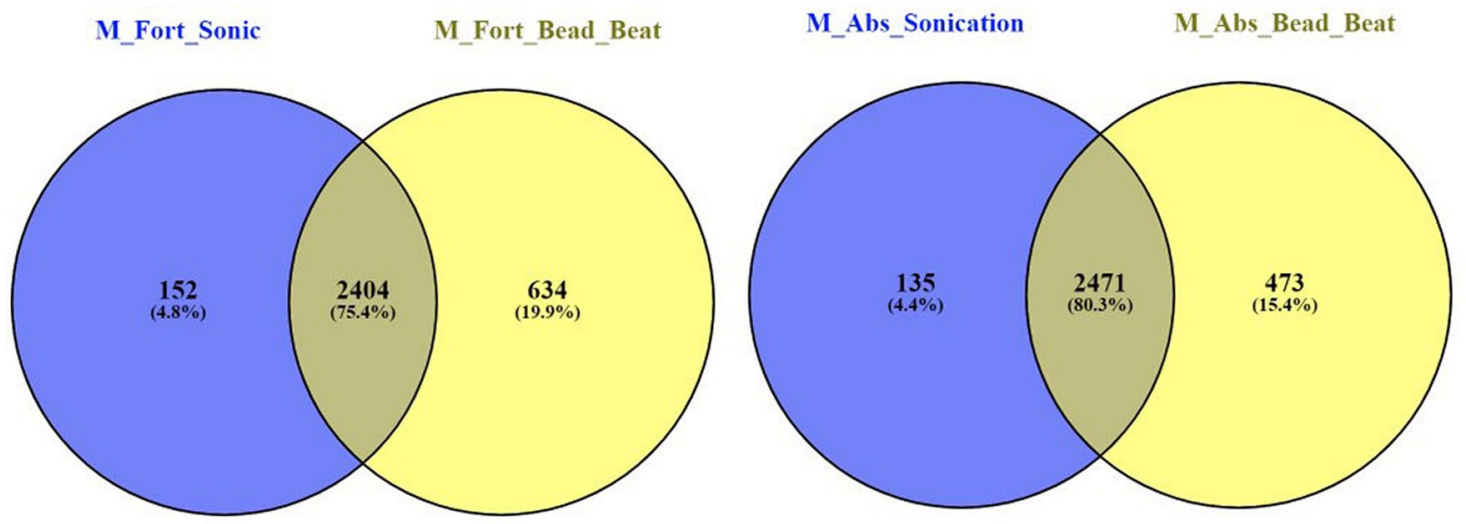

Fig. 6 Comparison of protein profile for sonication and bead-beating lysis methods with $\mathrm{Gu}-\mathrm{HCl}$ as extraction solvents for and $M$. fortuitum and M. abscessus

Funding This study was funded by Thermo Fisher Scientific.

\section{Compliance with ethical standards}

Conflict of interest The author(s) declare that they have no competing interests.

Ethical approval This article does not contain any studies with human participants or animals performed by any of the authors.

Open Access This article is licensed under a Creative Commons Attribution 4.0 International License, which permits use, sharing, adaptation, distribution and reproduction in any medium or format, as long as you give appropriate credit to the original author(s) and the source, provide a link to the Creative Commons licence, and indicate if changes were made. The images or other third party material in this article are included in the article's Creative Commons licence, unless indicated otherwise in a credit line to the material. If material is not included in the article's Creative Commons licence and your intended use is not permitted by statutory regulation or exceeds the permitted use, you will need to obtain permission directly from the copyright holder. To view a copy of this licence, visit http://creativecommons .org/licenses/by/4.0/.

\section{References}

1. McMurray DN (1996) Mycobacteria and Nocardia. In: Baron S (ed) Medical microbiology, 4th edn. University of Texas Medical Branch, Galveston

2. Brennan PJ (2003) Structure, function, and biogenesis of the cell wall of mycobacterium tuberculosis. Tuberculosis 83:91-97

3. Crick DC, Mahapatra S, Brennan PJ (2001) Biosynthesis of the arabinogalactan-peptidoglycan complex of mycobacterium tuberculosis. Glycobiology 11:107R-118R

4. Winn W, Allen S, Janda W, Koneman E, Procop G, Schreckenberger P, Woods $G$ (2005) Koneman's color atlas and textbook of diagnostic microbiology, 6 th edn. Lippincott Williama and Wilkins publication, USA, p 1090

5. Rabodoarivelo MS, Aerts M, Vandamme P, Palomino JC, Rasolofo V, Martin A (2016) Optimizing of a protein extraction method for mycobacterium tuberculosis proteome analysis using mass spectrometry. Int J Anal Chem, J Microbiol Methods 131:144147. https://doi.org/10.1016/j.mimet.2016.10.021

6. Michalski A, Damoc E, Hauschild JP, Lange O, Wieghaus A, Makarov A, Nagaraj N, Cox J, Mann M, Horning S (2011) Mass spectrometry-based proteomics using $\mathrm{Q}$ Exactive, a high-performance benchtop quadrupole Orbitrap mass spectrometer. Mol Cell Proteomics 10:1-12. https://doi.org/10.1074/mcp. M111.011015

7. Aebersold R, Mann M (2003) Mass spectrometry-based proteomics. Nature 422:198-207

8. Zhao L, Chen Y, Bajaj A, Eblimit A, Xu M, Soens Z, Wang F, Ge Z, Jung S, He F, Li Y, Wensel T, Qin J, Chen R (2016) Integrative subcellular proteomic analysis allows accurate prediction of human disease-causing genes. Genome Res 26:660-669. https ://doi.org/10.1101/gr.198911.115

9. Jaiswal N, Saraswat S, Ratnam M, Isailovic D (2012) Analysis of folate binding protein $\mathrm{N}$-linked glycans by mass spectrometry. J Proteome Res 11:1551-1560. https://doi.org/10.1021/pr200 6044

10. Saraswat S, Snyder B, Isailovic D (2012) Quantification of HPLC-separated peptides and proteins by spectrofluorimetric detection of native fluorescence and mass spectrometry. J Chromatgr B 902:70-77. https://doi.org/10.1016/j.jchro $\mathrm{mb} .2012 .06 .018$

11. Fenn JB, Mann M, Meng CK, Wong SF, Whitehouse CM (1989) Electrospray ionization for mass spectrometry of large molecules. Science 246:64-71

12. Karas M, Bachmann D, Bahr U, Hillenkamp F (1987) Int J Mass Spectrom lon Proc 78:53

13. Shevchenko G, Sjodin MO, Malmstrom D, Wetterhall M, Bergquist J (2010) Cloud-point extraction and delipidation of porcine brain proteins in combination with bottom-up mass spectrometry approaches for proteome analysis. J Proteome Res 9:3903-3911. https://doi.org/10.1021/pr100116k

14. Wang R, Prince JT, Marcotte EM (2005) Mass spectrometry of the M. smegmatis proteome: protein expression levels correlate with function, operons, and codon bias. Genome Res 15:1118-1126

15. He Z, De Buck J (2010) cell wall proteome of Mycobacterium smegmatis strain MC2 155. BMC Microbiol 10:1-10. https://doi. org/10.1186/1471-2180-10-121

16. Villén J, Gygi SP (2008) The SCX/IMAC enrichment approach for global phosphorylation analysis by mass spectrometry. Nat Protoc 3:1630-1638. https://doi.org/10.1038/nprot.2008.150 
17. Brennan PJ, Nikaido H (1995) The envelope of mycobacteria. Ann Rev Biochem 64:29-63

18. Chatterjee D (1997) The mycobacterial cell wall: structure, biosysnthesis and sites of drug action. Curr Opin Chem Biol $1: 579-588$

19. Esteban J, Molleja A, Cabria F, Soledad Jimenez M (2003) SDSPAGE for identification of species belonging to the Mycobacterium fortuitum complex. Clin Microbiol Infect 9:327-331

20. De Jong A, Hoentjen AH, Van Der Zanden AGM (1991) A rapid method for identification of mycobacterium species by polyacrylamide gel electrophoresis of soluble cell proteins. J Med Microbiol 34:1-5

21. Somoskovi A, Dormandy J, Rivenburg J, Pedrosa $M, M c B r i d e ~ M$, Salfinger M (2008) Direct comparison of the genotype MTBC and genomic deletion assays in terms of ability to distinguish between members of the mycobacterium tuberculosis complex in clinical isolates and in clinical specimens. J Clin Microbiol 46:1854-1857
22. Mather CA, Rivera SF, Butler-Wu SM (2014) Comparison of the Bruker Biotyper and Vitek MS Matrix-Assisted Laser Desorption Ionization-Time of Flight Mass Spectrometry Systems for Identification of Mycobacteria using Simplified Protein Extraction Protocols. J Clin Microbiol 52:130-138

23. Ripoll F, Pasek S, Schenowitz C, Dossat C, Barbe V, Rottman M, Macheras E, Heym B, Herrmann JL, Daffe M, Brosch R, Risler JL, Gaillard JL (2009) Non mycobacterial virulence genes in the genome of the emerging pathogen mycobacterium abscessus. PLoS ONE 4:1-12. https://doi.org/10.1371/journal.pone.0005660

Publisher's Note Springer Nature remains neutral with regard to jurisdictional claims in published maps and institutional affiliations. 